\title{
Conformational Transition of the Copolymer of Maleic Acid and $\alpha$-Methylstyrene in Aqueous Solution
}

\author{
Nobumichi OHNO \\ Department of Industrial Chemistry, Akita Technical College, \\ 1-1, Bunkyo-cho, Iizima, Akita 011, Japan.
}

(Received September 3, 1980)

\begin{abstract}
The $\mathrm{pH}$-induced conformational transition of an alternating copolymer of maleic acid and $\alpha$-methylstyrene in aqueous $\mathrm{NaCl}$ solutions has been investigated by $\mathrm{pH}$-titration, optical, viscometric, and dilatometric measurements. The relation between the intrinsic viscosity and the degree of dissociation of the primary carboxyl group shows a transition from a compact to an extended coil form. The volume change accompanying the transition at $0.009 \mathrm{M} \mathrm{NaCl}$ was found to increase from $-0.8 \mathrm{~cm}^{3}$ to $2.2 \mathrm{~cm}^{3}$ per monomole with increasing temperature from 15 to $35^{\circ} \mathrm{C}$. All results are compared with those of the maleic acid copolymer with styrene studied previously, and the influence of methyl groups on the transition is discussed.

KEY WORDS Conformational Transition / Maleic Acid Copolymer / $\alpha$ -

Methylstyrene / Hydrophobic Interaction / Volume Change /
\end{abstract}

It is known that hydrophobic polyelectrolytes such as poly(methacrylic acid) ${ }^{1-4}$ and copolymers of maleic acid with long chain aliphatic monomers ${ }^{5-7}$ in aqueous solution undergo, upon dissociation of carboxyl groups, a $\mathrm{pH}$-induced conformational transition from a compact to an extended coil form. This conformational transition is useful for investigating intramolecular hydrophobic interactions of globular proteins.

The $\mathrm{pH}$-induced conformational transition of an alternating copolymer of maleic acid and styrene (MA-St) ${ }_{n}$ has recently been studied. ${ }^{8-15}$ The thermodynamic analysis of the transition in aqueous $\mathrm{NaCl}$ was reported by us along with data from various measurements. ${ }^{9,13}$ The difference spectrum between the copolymer in the compact form and in the coil form showed that existence of buried phenyl groups in the interior of the molecule in the compact form. These groups are considered to be exposed after the transition. ${ }^{11}$ The hydrophobic domain in the compact-form copolymer was also recognized by studies on the interaction of (MA-St) $)_{n}$ with hydrophobic dyes such as acridine orange. ${ }^{15}$ From these results, the compact form at small degrees of dissociation $\left(\alpha_{1}\right)$ of the primary carboxyl group was concluded to be stabilized by the hydrophobic interaction between phenyl groups. Also, kinetic studies on the transition were carried out by optical methods. ${ }^{11,14}$

Preliminary studies on the similar conformational transition of an alternating copolymer of maleic acid and $\alpha$-methylstyrene (MA-MSt) ${ }_{n}$ were reported by us with data for unfractionated samples. ${ }^{16} \mathrm{~A}$ monomer in (MA-MSt) ${ }_{n}$ includes two hydrophobic groups: methyl and phenyl ones. It is of interest to compare the conformational transition of such a copolymer with that of (MA-St) ${ }_{n}$, which has only aromatic side chains.

In this paper, the conformational transition of (MA-MSt) ${ }_{n}$ in aqueous $\mathrm{NaCl}$ is investigated in further detail by $\mathrm{pH}$-titration, optical, viscometric and dilatometric measurements, mainly using the fractionated samples. The results are compared with those of (MA-St) ${ }_{n}$ reported previously, and then the influence of methyl groups on the transition is discussed.

\section{EXPERIMENTAL}

\section{Materials}

An alternating copolymer of maleic anhydride and $\alpha$-methylstyrene (MAn-MSt ${ }_{n}$ was prepared, in a manner similar to that described by, Seymour and Garner, ${ }^{17}$ from a mixture of one third mole of 
maleic anhydride and one third mole of $\alpha$-methylstyrene in $300 \mathrm{~cm}^{3}$ of purified decalin, $\alpha, \alpha^{\prime}$-azobisisobutyronitrile being used as the initiator. Maleic anhydride and $\alpha$-methylstyrene were purified by recrystallization from chloroform and by vacuum distillation, respectively. Copolymerization was carried out under oxygen-free nitrogen at $65^{\circ} \mathrm{C}$ for $48 \mathrm{~h}$. The copolymer was separated from the reaction mixture by filtration, washed with benzene, and reprecipitated from an acetone solution, and then dried under vacuum. Fractionation was achieved by the slow addition of chloroform to a dilute acetone solution of (MAn-MSt) ${ }_{n}$. This process gave five fractions (designated F-1 to F-5). The approximate molecular weight (MW) was estimated from intrinsic viscosities in tetrahydrofuran at $30^{\circ} \mathrm{C}$, using the relation ${ }^{18}$ for the copolymer of maleic anhydride with styrene. The alternating copolymer of (MA-MSt $)_{n}$ used here was obtained by hydrolysis of fraction F-2 (MW $=71000)$, fraction F-4 $(\mathrm{MW}=50000$ ), and the unfractionated (MAn$\mathrm{MSt})_{n}$ (designated $\mathrm{F}-0, \mathrm{MW}=40000$ ). The hydrolysis was carried out in $0.2 \mathrm{M}\left(\mathrm{mol} \mathrm{dm}^{-3}\right) \mathrm{NaOH}$ at $75^{\circ} \mathrm{C}$ for 3 days. The hydrolyzate was passed through a mixed-bed ion-exchange resin column (Amberlite CG-120 and CG-400) and then lyophilized and dried under vacuum at room temperature to give a spongy copolymer of (MA-MSt) ${ }_{n}$. The elementary analysis for (MA-MSt ${ }_{n}$ was performed with a Yanagimoto T-2 analyzer. Results: C, $67.18 \%$ and $\mathrm{H}, 6.00 \%$. The calculated values of $\left(\mathrm{C}_{13} \mathrm{H}_{14} \mathrm{O}_{4}\right)_{n}$ are $\mathrm{C}, 66.66 \%$ and $\mathrm{H}, 6.02 \%$. The other reagents used here and the preparation method of polymer stock solution were identical to those described previously. ${ }^{9}$

\section{Methods}

$\mathrm{pH}$ measurements were performed at 15 to $35^{\circ} \mathrm{C}$ under nitrogen using an Orion digital ionalyzer model 801A equipped with an Orion 91-01 glass electrode and a 90-01 calomel electrode, the inner solution of which was $3.3 \mathrm{M}$ aqueous $\mathrm{KCl}$. The temperature was controlled within $\pm 0.01^{\circ} \mathrm{C}$. The $\mathrm{KCl}$ liquid-junction, the standardization of the instrument, and the procedure of $\mathrm{pH}$-titration have been described previously. ${ }^{9,19}$ The analysis of titration data was also identical to that described previously. ${ }^{9}$ The total molarity of primary carboxyl groups was determined from the first peak of the differential titration curve. The correction for hy- drogen ion concentration was made directly from a blank titration; the results at various ionic strengths agree very closely with the previous data. ${ }^{9,20}$ The ionic strength $I$ (in $\mathrm{mol} \mathrm{dm}^{-3}$ ) of the solution was taken as the concentration of added $\mathrm{NaCl}$.

Viscosity measurements were made at 25 $( \pm 0.006)^{\circ} \mathrm{C}$ with a Ubbelohde viscometer having a flow time of 101.9 or $102.2 \mathrm{sec}$ for the solvent at $25^{\circ} \mathrm{C}$. Corrections for kinetic energy and rate of shear were found to be negligible.

Optical absorption and difference spectra were obtained at 5 to $25^{\circ} \mathrm{C}$ by use of a Hitachi doublebeam spectrophotometer model 200. The temperature of both the sample and reference was controlled within $\pm 0.1{ }^{\circ} \mathrm{C}$.

Volume changes were measured at 15 to $35^{\circ} \mathrm{C}$ in a similar manner to that described previously, ${ }^{9}$ with a Carlsberg type dilatometer immersed in a wellcontrolled thermostat $\left( \pm 0.001{ }^{\circ} \mathrm{C}\right)$.

\section{RESULTS}

The titration curve for fraction F-2 of (MA$\mathrm{MSt})_{n}$ in a $0.0878 \mathrm{M} \mathrm{NaCl}$ aqueous solution at $25^{\circ} \mathrm{C}$ is shown in Figure 1. The pattern of the curve shows, as with that of (MA-St $)_{n},{ }^{8}$ a pronounced inflection point at $\alpha_{1}=1.0$. This indicates that the copolymer has two distinguishable carboxyl groups.

The apparent dissociation constant of primary carboxyl groups $\left(\mathrm{p} K_{1}\right)$ was calculated as a function of $\alpha_{1}$. The error in $\mathrm{p} K_{1}$ values is less than $0.03 \mathrm{pK}$ units. The modified $\mathrm{pH}$-titration curves for fraction $\mathrm{F}-2$ at $25^{\circ} \mathrm{C}$ and various ionic strengths are shown in Figure 2; these curves show anomalous behavior around $\alpha_{1}=0.25$ and greatly resemble the case of $(\mathrm{MA}-\mathrm{St})_{n}$ reported earlier. ${ }^{9}$ Similar titration curves were also obtained for unfractionated $\mathrm{F}-0$ and fraction F-4. The polymer concentration $\left(C_{\mathrm{p}}\right)$ dependence of the titration curve was found to be very small in the range of $C_{\mathrm{p}}$ from 0.0048 to 0.0149 monomole $\mathrm{dm}^{-3}$ at constant ionic strength. Moreover, there was no precipitation or turbidity in the deionized polymer solutions to which $\mathrm{NaCl}$ had been added. Consequently, the anomalous behavior of $\mathrm{p} K_{1}$ shown in Figure 2 indicates a conformational transition which may be related to intramolecular hydrophobic interactions between phenyl and/or methyl groups. The values of the intrinsic dissociation constant of primary carboxyl groups $\left(\mathrm{p} K_{1}^{\circ}\right.$ ) estimated from Figure 2 seem con- 


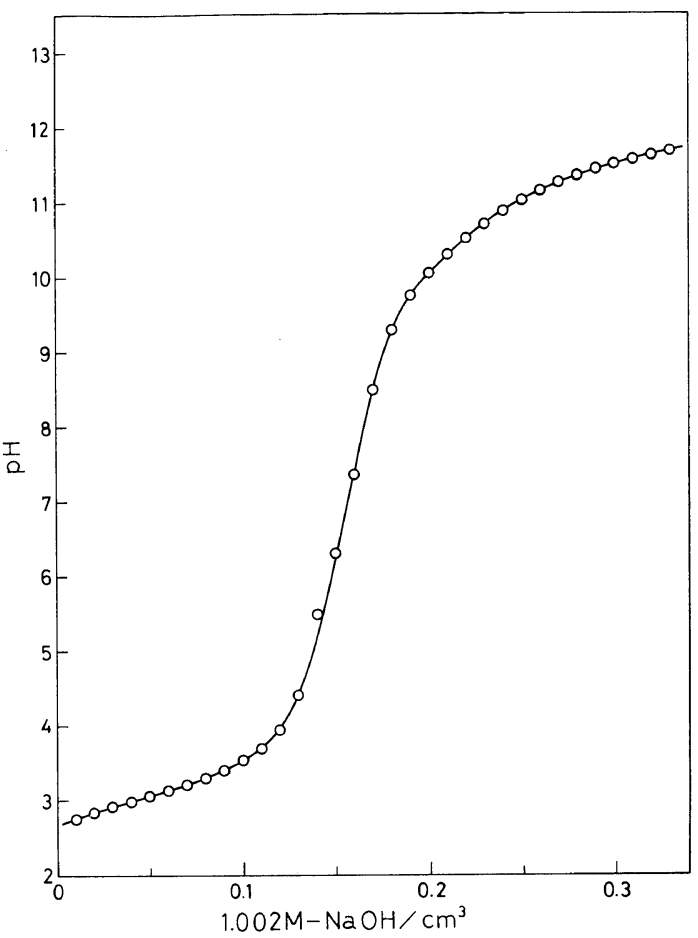

Figure 1. $\mathrm{pH}$-titration curve of (MA-MSt $)_{n}(\mathrm{~F}-2)$ in aqueous $0.0878 \mathrm{M} \mathrm{NaCl}$ at $25^{\circ} \mathrm{C}$. Polymer concn, 0.01490 monomole $\mathrm{dm}^{-3}$.

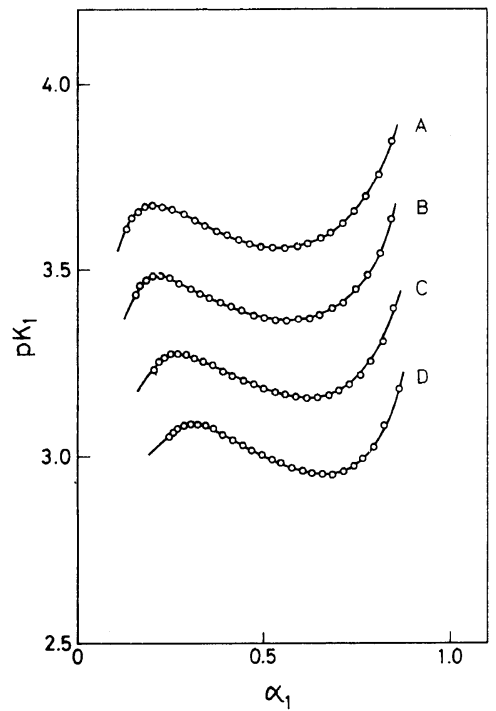

Figure 2. Modified pH-titration curves of (MA-MSt $)_{n}$ $(\mathrm{F}-2)$ in aqueous $\mathrm{NaCl}$ at various ionic strengths at $25^{\circ} \mathrm{C}$. $\mathrm{NaCl}$ concn: (A), $0.0092 \mathrm{M}$; (B), $0.0298 \mathrm{M}$; (C), $0.0878 \mathrm{M}$; (D), 0.2739 M. Polymer concn, 0.01490 monomole $\mathrm{dm}^{-3}$.

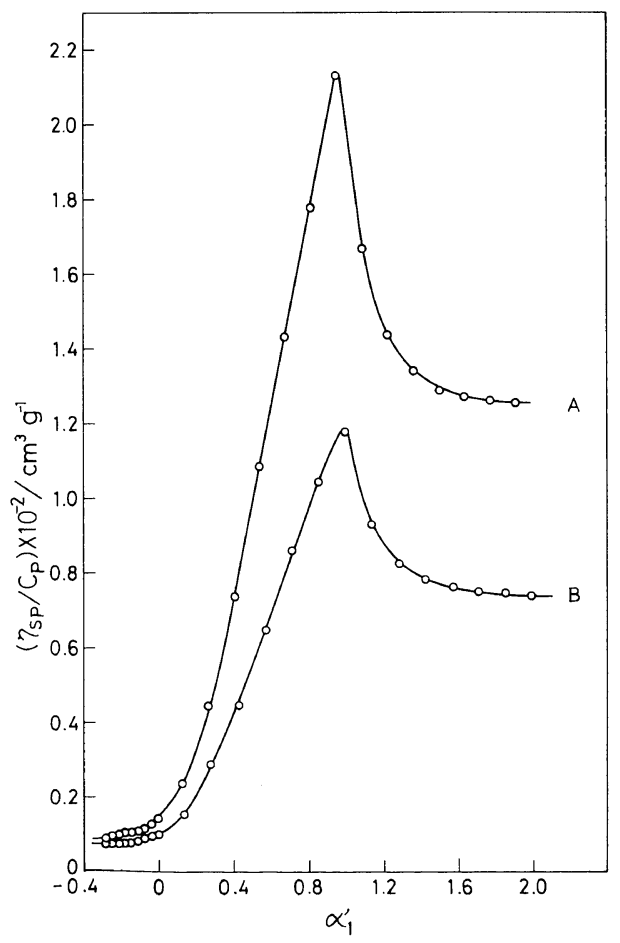

Figure 3. Dependence of reduced viscosity on the degree of neutralization for (MA-MSt) ${ }_{n}$ in aqueous $0.0878 \mathrm{M} \mathrm{NaCl}$ at $25^{\circ} \mathrm{C}$. (A), Fraction F-2. Polymer concn, $3.116 \times 10^{-3} \mathrm{~g} \mathrm{~cm}^{-3}$. (B), Fraction F-4. Polymer concn, $2.984 \times 10^{-3} \mathrm{~g} \mathrm{~cm}^{-3}$.

siderably smaller than those for (MA-St) ${ }_{n} \cdot{ }^{9,12}$ The temperature dependence of the $\mathrm{pH}$-titration of (MA-MSt) ${ }_{n}$ in $0.0878 \mathrm{M} \mathrm{NaCl}$ aqueous solution is, as in the case of (MA-St $)_{n}{ }^{13}$ scarcely recognized in the temperature range 15 to $35^{\circ} \mathrm{C}$.

Viscometric titration curves for fraction F-2 and $\mathrm{F}-4$ in $0.0878 \mathrm{M} \mathrm{NaCl}$ aqueous solutions at $25^{\circ} \mathrm{C}$ are shown in Figure 3, in which the data in the range of $\alpha_{1}{ }^{\prime}$ (degree of neutralization of the primary carboxyl group) below 0 were obtained by back-titration with $\mathrm{HCl}$. The reduced viscosity $\left(\eta_{\mathrm{sp}} / C_{\mathrm{p}}\right)$ is extremely low and constant at $\alpha_{1}{ }^{\prime}$ below 0.1 , but in the range of $\alpha_{1}{ }^{\prime}$ between 0.1 and 1.0 , it increases sharply with increasing $\alpha_{1}{ }^{\prime}$. This viscometric behavior differs from the case of a copolymer of maleic acid with ethylene $^{21}$ for which the reduced viscosity increases smoothly with increasing $\alpha_{1}{ }^{\prime}$ over the range of $\alpha_{1}{ }^{\prime}$ below 1.0. In addition, Figure 3 shows a sharp maximum of reduced viscosity at $\alpha_{1}{ }^{\prime}=1.0$. This remarkable property, which may be correlated with the intramolecular hydrogen bonding in maleic acid 


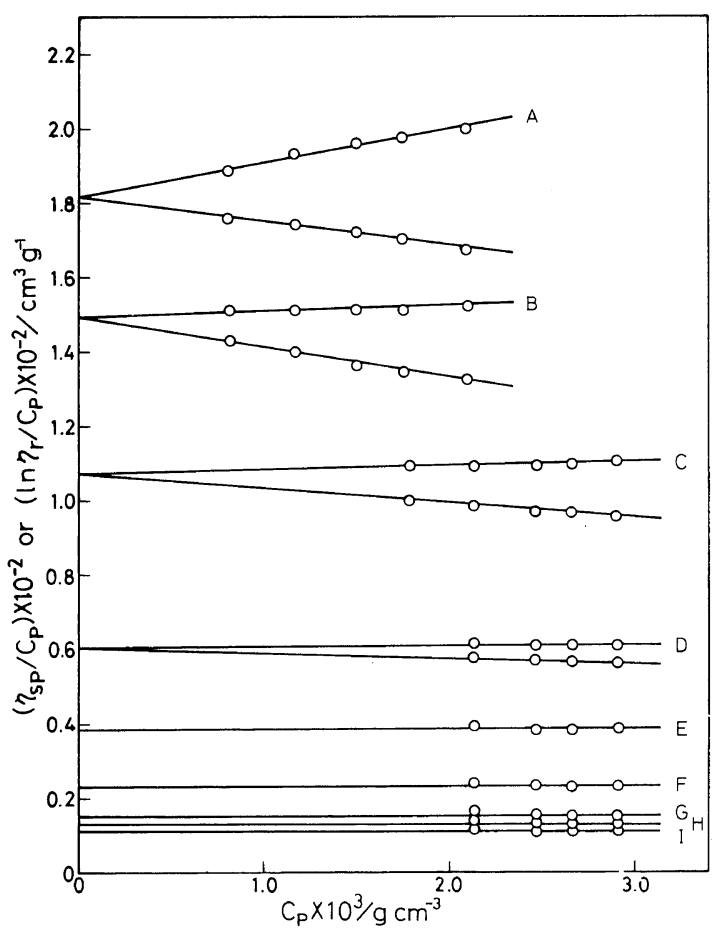

Figure 4. Dependence of selected viscosity on polymer concentration for (MA-MSt $)_{n}(\mathrm{~F}-2)$ at various degrees of neutralization at $25^{\circ} \mathrm{C}$. Degrees of neutralization: (A), 1.0; (B), 0.78; (C), 0.56; (D), 0.34; (E), 0.23; (F), 0.11; (G), $0 ;(\mathrm{H}),-0.07 ;(\mathrm{I}),-0.21 . \mathrm{NaCl}$ concn, $0.0909 \mathrm{M}$.

residues (see DISCUSSION), is similar to that of copolymers of maleic acid with styrene ${ }^{8}$ and with alkyl vinyl ethers. ${ }^{6,22}$

Figure 4 shows some typical examples of viscosity plots for fraction F-2 against $C_{\mathrm{p}}$ at $25^{\circ} \mathrm{C}, I=0.0909$, and various $\alpha_{1}{ }^{\prime}$. In the range of $\alpha_{1}{ }^{\prime}<0.34$ and $C_{\mathrm{p}}<2 \times 10^{-3} \mathrm{~g} \mathrm{~cm}^{-3}, \eta_{\mathrm{sp}} / C_{\mathrm{p}}$ increases slightly with decreasing $C_{\mathrm{p}}$. Since this behavior seems due to enhanced dissociation with dilution, ${ }^{23,24}$ the intrinsic viscosity $[\eta]$ was determined by a linear extrapolation of the data above $2 \times 10^{-3} \mathrm{~g} \mathrm{~cm}^{-3}$. The values of $\eta_{\mathrm{sp}} / C_{\mathrm{p}}$ at $\alpha_{1}{ }^{\prime}$ below 0.34 and $C_{\mathrm{p}}$ above $2 \times 10^{-3} \mathrm{~g} \mathrm{~cm}^{-3}$ are almost independent of $C_{\mathrm{p}}$. This finding also supports the previous conclusion that the $\mathrm{pH}$-induced anomaly is due not to molecular aggregation but to intramolecular interaction.

The relation between $[\eta]$ and $\alpha_{1}$ for fraction F-2 in a $0.0909 \mathrm{M} \mathrm{NaCl}$ aqueous solution at $25^{\circ} \mathrm{C}$ is shown in Figure 5. The filled circles indicate data obtained by back-titration with $\mathrm{HCl}$. Although some unavoidable error was involved in the calculation of

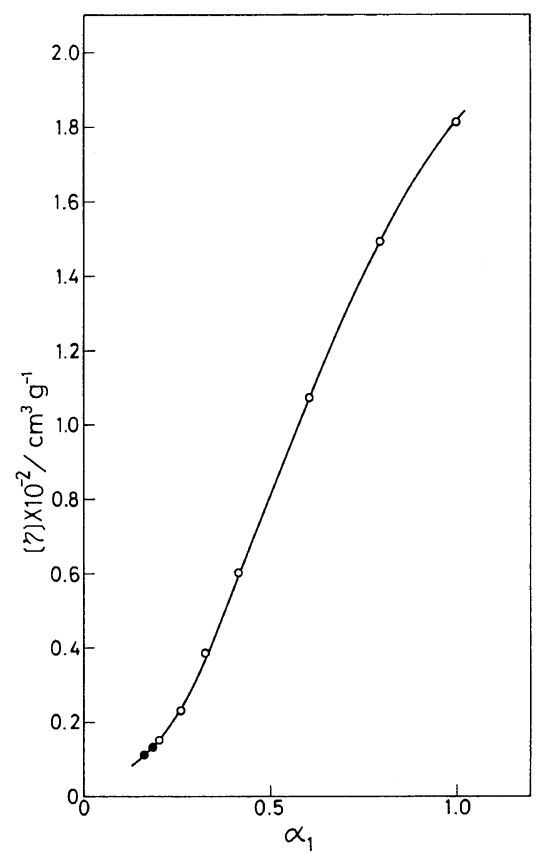

Figure 5. Dependence of intrinsic viscosity on the degree of dissociation for (MA-MSt) $)_{n}(\mathrm{~F}-2)$ in aqueous $0.0909 \mathrm{M} \mathrm{NaCl}$ at $25^{\circ} \mathrm{C}$.

low $\alpha_{1}$, the curve clearly shows the $\mathrm{pH}$-induced conformational transition from the compact form to the extended coil form. But the compact form of $(\mathrm{MA}-\mathrm{MSt})_{n}$ at low $\alpha_{1}$ does not seem to be as compact as that of (MA-St $)_{n}{ }^{9}$

The optical absorption spectrum and difference spectrum for fraction $\mathrm{F}-2$ in aqueous $\mathrm{NaCl}$ at $25^{\circ} \mathrm{C}$ and $I=0.0092$ are shown in Figure 6. The absorption spectrum (A) of phenyl groups in (MA-MSt) at $\alpha_{1}{ }^{\prime}=0$ has peaks at 253,259 and $264 \mathrm{~nm}$, and these absorption peaks each shift to a lower wavelength and the intensity at each peak decreases slightly as $\alpha_{1}{ }^{\prime}$ increases to $\alpha_{1}{ }^{\prime}=1.0$. The difference spectrum (B) of (MA-MSt) ${ }_{n}$ at $\alpha_{1}{ }^{\prime}=0$, the copolymer completely in the extended coil form with $\alpha_{1}{ }^{\prime}=0.952$ being used as a reference, has peaks at 234, $261 \mathrm{~nm}$ and other wavelengths. The peak at $234 \mathrm{~nm}$ is associated with the charged carboxyl groups and that at $261 \mathrm{~nm}$ with the phenyl groups.

In Figure 7 , plots of the difference in molar extinction coefficient at $261 \mathrm{~nm}\left(\Delta \varepsilon_{261}\right)$ against $\alpha_{1}$ are shown at $I=0.0294$ for the temperature range 5 to $25^{\circ} \mathrm{C}$. The value of $\Delta \varepsilon_{261}$ decreases in a reversed sigmoidal fashion with increasing $\alpha_{1}$, and may 


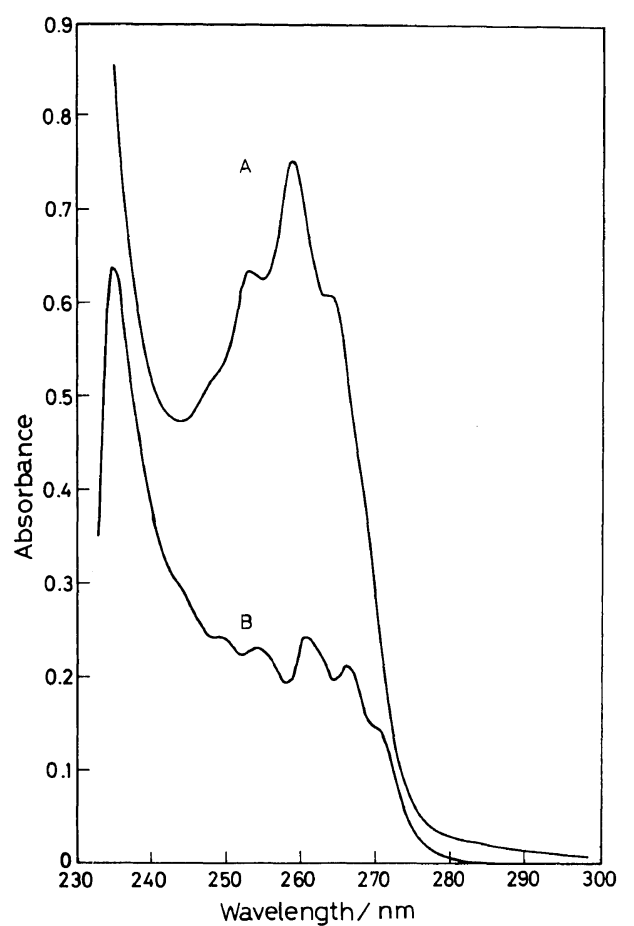

Figure 6. Optical absorption and difference spectra of (MA-MSt) ${ }_{n}$ (F-2) in aqueous $0.0092 \mathrm{M} \mathrm{NaCl}$ at $25^{\circ} \mathrm{C}$. Degree of neutralization of sample, $\alpha_{1}{ }^{\prime}=0$.

(A), Absorption spectrum. Polymer concn, 0.0041 monomole $\mathrm{dm}^{-3}$.

(B), Difference spectrum. Polymer concn. 0.0156 monomole $\mathrm{dm}^{-3}$.

The solution at $\alpha_{1}{ }^{\prime}=0.952$ was used as a reference.

reflect the transition.

In Figures 8, 9, and 10, the volume changes $(\Delta V)$ observed in the back-titration of monosodium salts of (MA-MSt $)_{n}(\mathrm{~F}-0)$ in $0.009 \mathrm{M} \mathrm{NaCl}$ aqueous solution with $0.5 \mathrm{M} \mathrm{HCl}$ are shown for the temperature range 15 to $35^{\circ} \mathrm{C}$. The value of $\Delta V$ is the volume change measured when $15 \mathrm{~cm}^{3}$ of 0.01525 monomole $\mathrm{dm}^{-3}$ copolymer solution is mixed with $3 \mathrm{~cm}^{3}$ solvent containing varying amounts of $\mathrm{HCl}$. It is convenient to represent Figures 8, 9 or 10 by three straight lines instead of a smooth curve. The region between $\mathrm{E}$ and $\mathrm{C}$ represents the transition zone. The volume changes for the transition $\left(\Delta V_{\mathrm{t}}\right)$ and for the binding reaction of the monoprotonated (MA$\mathrm{MSt})_{n}$ with hydrogen ion $\left(\Delta V /\right.$ bound $\left.\mathrm{H}^{+}\right)$were estimated by the same method as that reported previously. ${ }^{9}$ The results are summarized in Table I.

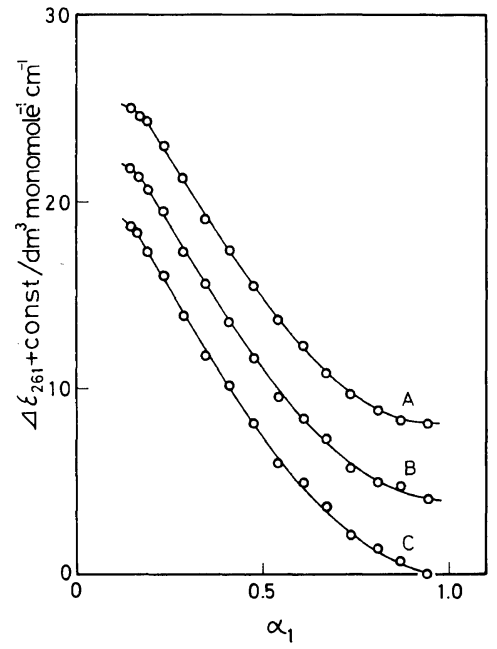

Figure 7. Plots of difference in molar extinction coefficient at $261 \mathrm{~nm}$ against degree of dissociation for (MA$\mathrm{MSt})_{n}(\mathrm{~F}-2)$ in aqueous $0.0294 \mathrm{M} \mathrm{NaCl}$ at various temperatures. Temperature: (A), $25^{\circ} \mathrm{C} ;(\mathrm{B}), 15^{\circ} \mathrm{C} ;(\mathrm{C}), 5^{\circ} \mathrm{C}$. Shifting constant: (A), 8; (B), 4; (C), 0. Polymer concn: 0.0137 monomole $\mathrm{dm}^{-3}$. The solution at $\alpha_{1}=0.941$ and each temperature was used as a reference.

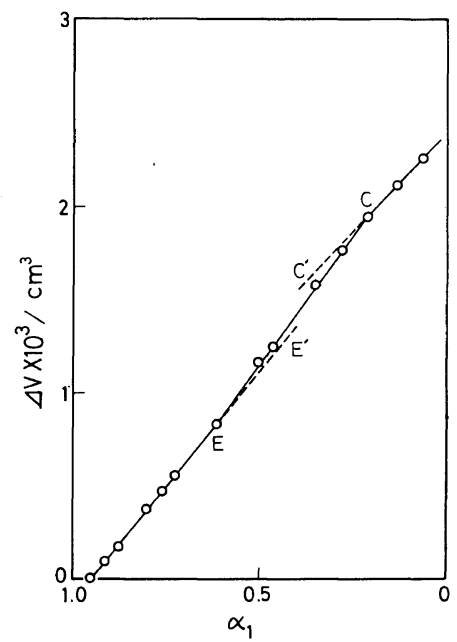

Figure 8. Volume change of monosodium salt of (MA-MSt) ${ }_{n}(\mathrm{~F}-0)$ during titration with $\mathrm{HCl}$ as a function of the degree of dissociation $\alpha_{1}$ at $15^{\circ} \mathrm{C} . \mathrm{NaCl}$ concentration $0.009 \mathrm{M} ; \alpha_{1}=0.95$ for the initial solution. $\Delta V$ is the actual volume change when $15 \mathrm{~cm}^{3}$ of 0.01525 monomole $\mathrm{dm}^{-3}$ polymer solution is mixed with $3 \mathrm{~cm}^{3}$ solvent containing varying amounts of $\mathrm{HCl}$. 


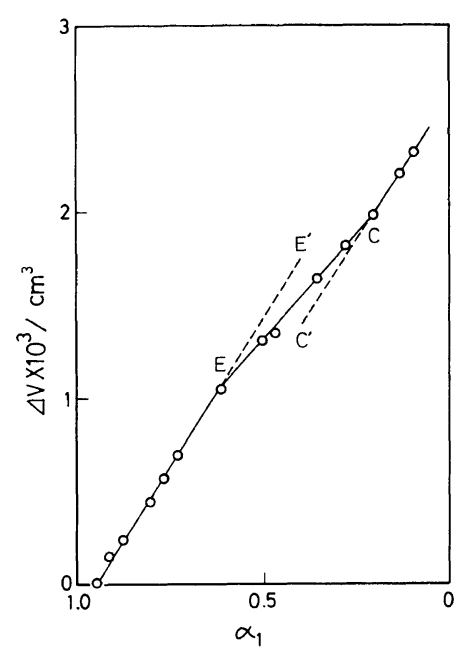

Figure 9. Volume change of monosodium salt of (MA-MSt) $)_{n}(\mathrm{~F}-0)$ during titration with $\mathrm{HCl}$ as a function of the degree of dissociation $\alpha_{1}$ at $25^{\circ} \mathrm{C}$. Other conditions are the same as in Figure 8.

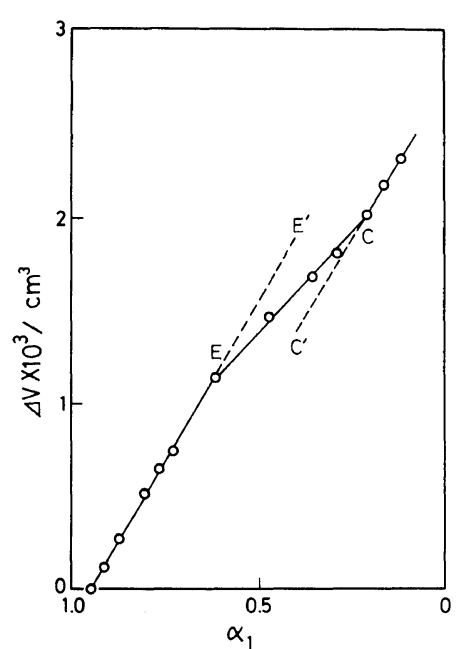

Figure 10. Volume change of monosodium salt of (MA-MSt) ${ }_{n}(\mathrm{~F}-0)$ during titration with $\mathrm{HCl}$ as a function of the degree of dissociation $\alpha_{1}$ at $35^{\circ} \mathrm{C}$. Other conditions are the same as in Figure 8.

Table I. Volume changes determined by dilatometry of (MA-MSt) $)_{n}$ during titration

\begin{tabular}{|c|c|c|c|c|}
\hline \multirow{3}{*}{$\frac{\text { Temp }}{{ }^{\circ} \mathrm{C}}$} & \multirow{3}{*}{$\frac{\mathrm{NaCl} \text { concn }}{\mathrm{mol} \mathrm{dm^{-3 }}}$} & \multicolumn{2}{|c|}{$\left(\Delta V /\right.$ bound $\left.\mathrm{H}^{+}\right) / \mathrm{cm}^{3}$ monomole ${ }^{-1}$} & \multirow{2}{*}{$\Delta V_{\mathrm{t}}$} \\
\hline & & \multirow{2}{*}{$\begin{array}{l}\text { Extended } \\
\text { coil form }\end{array}$} & \multirow{2}{*}{$\begin{array}{l}\text { Compact } \\
\text { form }\end{array}$} & \\
\hline & & & & $\mathrm{cm}^{3}$ monomole ${ }^{-1}$ \\
\hline 15 & 0.009 & 10.9 & 9.3 & 0.8 \\
\hline 25 & 0.009 & 14.0 & 13.3 & -1.6 \\
\hline 35 & 0.009 & 15.0 & 14.4 & -2.2 \\
\hline 25 & 0.09 & 11.8 & 11.0 & -0.8 \\
\hline
\end{tabular}

\section{DISCUSSION}

All the results from $\mathrm{pH}$-titration, viscometry, optical titration, and dilatometry made here indicate the $\mathrm{pH}$-induced conformational transition of (MA-MSt $)_{n}$ from the compact form to the extended coil one. The short-range interaction between hydrophobic groups, phenyl and/or methyl ones, seems to be responsible for stabilization of the compact form at lower $\alpha_{1}$. The compact form is converted to the extended coil as the long-range electrostatic interaction becomes predominant at higher $\alpha_{1}$. Figure 7 indicates that either the phenyl groups buried in the hydrophobic domain are exposed after the transition or the environment around the phenyl groups is varied with the transition. However, from the present data it is difficult to clarify the contribution of methyl groups to the stabilization of the compact form of (MA-MSt) ${ }_{n}$.

The standard free energy change $\left(\Delta G_{\mathrm{t}}{ }^{\circ}\right)$ per monomole for the transition of a hypothetical uncharged molecule is given by the equation ${ }^{1,25}$

$$
\Delta G_{\mathrm{t}}^{\circ}=2.3 R T \int_{0}^{1}\left(\mathrm{p} K_{1}-\mathrm{p} K_{1}{ }^{\prime}\right) \mathrm{d} \alpha_{1}
$$

where $\mathrm{p} K_{1}{ }^{\prime}$ is the hypothetical $\mathrm{p} K_{1}$ value over the entire range of $\alpha_{1}$ for the extended coil form of lower charge density. In Figure 11, the modified pH-titration curve for fraction F-2 at $I=0.0092$ is represented along with that of $(\mathrm{MA}-\mathrm{St})_{n}$ at the same ionic strength. To determine the value of $\mathrm{p} K_{1}{ }^{\circ}$ for (MA-MSt) ${ }_{n}$, back-titration with $\mathrm{HCl}$ was employed for the deionized solution, but no appropriate value could be obtained because low $\mathrm{pH}$ values lead to 


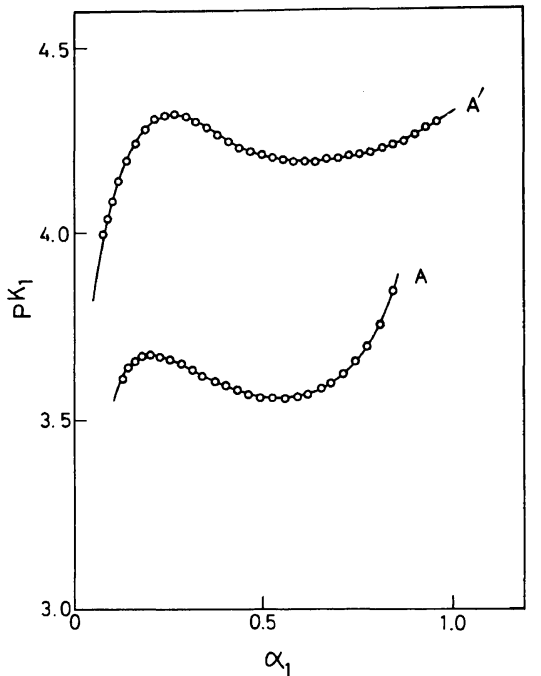

Figure 11. Modified pH-titration curves for (MA$\mathrm{MSt})_{n}$ and for (MA-St) ${ }_{n}$ in aqueous $0.0092 \mathrm{M} \mathrm{NaCl}$ at $25^{\circ} \mathrm{C}$.

(A): (MA-MSt) $)_{n}$, the same ploting as in Figure 2.

$\left(\mathrm{A}^{\prime}\right)$ : $(\mathrm{MA}-\mathrm{St})_{n}$, the same ploting as in Figure 1 in ref 9.

large errors in calculation. Therefore, an accurate estimation of the value of $\Delta G_{\mathrm{t}}^{\circ}$ for (MA-MSt) is difficult, but Figure 11 indicates that the value of $\Delta G_{\mathrm{t}}^{\circ}$ for (MA-MSt) ${ }_{n}$ is smallar than that ${ }^{9}$ of $(\mathrm{MA}-\mathrm{St})_{n}$.

The dependence of the fraction $\left(f_{\mathrm{c}}\right)$ of monomeric units in the coil form of (MA-MSt) $)_{n}$ on $\alpha_{1}$ was calculated from the $\mathrm{pH}$-titration data, ${ }^{1,26}$ and is shown in Figure 12. The $\alpha_{1}$-value at the midpoint for the transition of (MA-MSt) ${ }_{n}$ is lower than that ${ }^{13}$ of (MA-St) $)_{n}$.

The same relation is also recognized from the results of dilatometry by a comparison of the transition region of (MA-MSt) ${ }_{n}$ with that ${ }^{9}$ of $(\mathrm{MA}-\mathrm{St})_{n}$.

As noted above, though the hydrophobicity of the molecule as a whole increases by the addition of methyl groups to the main chain, all results indicate that the compact form of (MA-MSt) ${ }_{n}$ at low $\alpha_{1}$ is more extended and less stable than that of $(\mathrm{MA}-\mathrm{St})_{n}$. This finding differs from the results $\mathrm{s}^{5-7}$ for maleic acid and alkyl vinyl ether copolymers, in which the stability of the compact form increases with an increase in the number of methylene groups on the same side chain. In the present case, it is considered that both methyl and phenyl groups in a monomeric unit coexist with difficulty in the hy-

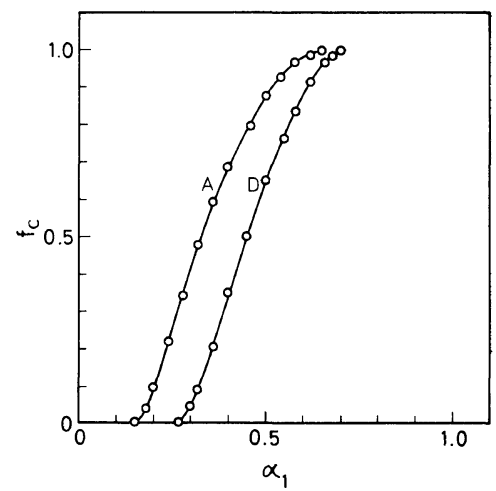

Figure 12. Fraction of monomeric units in the coil form of $(\mathrm{MA}-\mathrm{MSt})_{n}$ at $25^{\circ} \mathrm{C}$. $\mathrm{NaCl}$ concn: (A), $0.0092 \mathrm{M}$; (D), $0.2739 \mathrm{M}$.

drophobic domain of the compact form. This steric hindrance between two hydrophobic groups in methylstyrene in the formation of the hydrophobic domain may be one mechanism which weakens the hydrophobic interaction in the compact form and expands the molecular dimensions.

The volume change $\Delta V_{\mathrm{t}}$ for the transition was about $-1.6 \mathrm{~cm}^{3}$ and $-0.8 \mathrm{~cm}^{3}$ per monomole at $25^{\circ} \mathrm{C}$ in $0.009 \mathrm{M}$ and $0.09 \mathrm{M} \mathrm{NaCl}$ aqueous solutions, respectively. These values contrast with the positive value ${ }^{9}$ of $\Delta V_{\mathrm{t}}$ for (MA-St) ${ }_{n}$. Furthermore, it is of interest that the value of $\Delta V_{\mathrm{t}}$ increases from $-2.2 \mathrm{~cm}^{3}$ to $0.8 \mathrm{~cm}^{3}$ per monomole with decreasing temperature in the range of 35 to $15^{\circ} \mathrm{C}$, even though the temperature dependence of $\mathrm{pH}$-titration and optical titration is not so remarkable in the same temperature range. These results are too complicated to be interpreted clearly. However, such factors may be considered as the water structure around the molecule, ${ }^{27}$ the breaking effect of charged carboxyl groups on this structure, and the formation of a void volume ${ }^{28}$ participate in the occurrence of $\Delta V_{\mathrm{t}}$.

Dubin and Strauss ${ }^{6,7}$ have given the following formula for the titration data of poly(diprotic acid)

$(0.434 / R T)\left(\partial G_{\text {ion }} / \partial \alpha_{1}\right)+\mathrm{p} K_{1}{ }^{\circ}=\mathrm{pH}$

$$
+\log \left\{\left(\frac{1-\alpha_{1}}{2 \alpha_{1}}\right)+\left[\left(\frac{1-\alpha_{1}}{2 \alpha_{1}}\right)^{2}+\frac{K_{2}^{\circ}}{K_{1}^{\circ}}\left(\frac{2-\alpha_{1}}{\alpha_{1}}\right)\right]^{1 / 2}\right\}
$$

where $K_{1}^{\circ}$ and $K_{2}^{\circ}$ are the primary and secondary intrinsic dissociation constants of a diprotic acid residue and $\mathrm{d} G_{\text {ion }}$ is the differential change in the 
electrostatic and conformational free energy accompanying a differential change in $\alpha_{1}$. The ratio of $K_{2}{ }^{\circ}$ to $K_{1}{ }^{\circ}$ may then be defined as,

$$
K_{2}^{\circ} / K_{1}^{\circ}=10^{2\left(\mathrm{pK}_{1, \alpha=1}-\mathrm{pH}_{\alpha=1}\right)}
$$

where $\mathrm{p} K_{1, \alpha=1}$ is the value obtained by the smooth extrapolation of $\mathrm{p} K_{1}$ to $\alpha_{1}=1.0$ from the range of $\alpha_{1}$ over which eq 2 is valid. The $K_{2}{ }^{\circ} / K_{1}{ }^{\circ}$ ratios at $25^{\circ} \mathrm{C}$ and $I=0.0878$ are $2.8 \times 10^{-7}$ and $4.5 \times 10^{-5}$ for $(\mathrm{MA}-\mathrm{MSt})_{n}$ and (MA-St $)_{n}$, respectively.

For symmetric dicarboxylic acid, Dygert, Muzii, and Saroff ${ }^{29}$ pointed out that large values of $K_{1}{ }^{\mathrm{a}} / 4 K_{2}{ }^{\mathrm{a}}$ over 300 , where $K_{1}{ }^{\mathrm{a}}$ and $K_{2}{ }^{\mathrm{a}}$ are association constants for the unprotonated and monoprotonated species, respectively, usually indicate intramolecular hydrogen bonding and that a strong intramolecular hydrogen bond can exist in aqueous solution. If such a relation is applicable to maleic acid copolymers, the values of $K_{1}{ }^{\mathrm{a}} / 4 K_{2}{ }^{\mathrm{a}}$, i.e., $\left(1 / K_{2}{ }^{\circ}\right) / 4\left(1 / K_{1}{ }^{\circ}\right)$, are about $9.0 \times 10^{5}$ and $5.6 \times 10^{3}$ for (MA-MSt) ${ }_{n}$ and (MA-St) ${ }_{n}$, a strong intramolecular hydrogen bond may exist in both copolymers in the primary dissociation region. The hydrogen bonding is broken in the process of dissociation of secondary carboxyl groups, and this may result in an increase in the freedom of rotation around the single bonds between the $\mathrm{CH}$ groups carrying the carboxylate groups. Consequently, the flexibility of the polymer backbone becomes greater. The maxima at $\alpha_{1}{ }^{\prime}=1.0$ of reduced viscosity for (MA$\mathrm{MSt})_{n}$ and $(\mathrm{MA}-\mathrm{St})_{n}$ may be related to the disappearance of the hydrogen bonding and/or the specific binding ${ }^{30}$ of sodium ions to the copolymers above $\alpha_{1}{ }^{\prime}=1.0$.

Acknowledgements. The author wishes to thank Professor S. Sugai of Hokkaido University for his valuable comments and suggestions. $\mathrm{He}$ is also indebted to Dr. K. Nitta and Dr. M. Sakurai of Hokkaido University for their helpful guidance. This work was supported by a Grant-in-Aid of Scientific Research from the Ministry of Education, Science and Culture of Japan.

\section{REFERENCES}

1. J. C. Leyte and M. Mandel, J. Polym. Sci., A, 2, 1879 (1964).

2. M. Nagasawa, T. Murase, and K. Kondo, J. Phys. Chem., 69, 4005 (1965).
3. V. Crescenzi, Adv. Polym. Sci., 5, 358 (1968).

4. E. Okamoto and Y. Wada, J. Polym. Sci., Polym. Phys. Ed., 12, 2413 (1974).

5. P. L. Dubin and U. P. Strauss, J. Phys. Chem., 71, 2757 (1967).

6. P. L. Dubin and U. P. Strauss, J. Phys. Chem., 74, 2842 (1970).

7. P. L. Dubin and U. P. Strauss, in "Polyelectrolytes and Their Applications," Vol. 2, A. Rembaum and E. Sélégny, Ed., Reidel, Dordrecht, 1975, p 3.

8. N. Ohno, K. Nitta and S. Sugai, Kobunshi Kagaku, 28, 671 (1971).

9. N. Ohno, K. Nitta, S. Makino, and S. Sugai, J. Polym. Sci., Polym. Phys. Ed., 11, 413 (1973).

10. P. A. Demchenko and V. P. Boiko, Vysokomol. Soedin., Ser. A, 15, 2320 (1973).

11. S. Sugai, N. Ohno, and K. Nitta, Macromolecules, 7, 961 (1974).

12. S. Sasaki an A. Minakata, Rep. Prog. Polym. Phys. Jpn., 19, 65 (1976).

13. T. Oku'da, N. Ohno, K. Nitta, and S. Sugai, $J$. Polym. Sci., Polym. Phys. Ed., 15, 749 (1977).

14. N. Ohno, T. Okuda, K. Nitta, and S. Sugai, J. Polym. Sci., Polym. Phys. Ed., 16, 513 (1978).

15. N. Ohno, Nippon Kagaku Kaishi, 1137 (1978).

16. S. Sugai and N. Ohno, Abstracts, U.S.-Japan Joint Seminar on the Electrolytic Aspects of Biopolymers and Biological Systems, Honolulu, June, 1979, p 21.

17. R. B. Seymour and D. P. Garner, Polymer, 17, 21 (1976).

18. R. Endo, T. Hinokuma, and M. Takeda, J. Polym. Sci., A-2, 6, 665 (1968).

19. K. Nitta, M. Yoneyama, and N. Ohno, Biophys. Chem., 3, 323 (1975).

20. S. Sugai and K. Nitta, in "Kobunshi Jikkengaku," Vol. 13, The Society of Polymer Science, Japan, Ed., Kyoritsu Publishing Co., Ltd., Tokyo, 1978, Section 3.

21. N. Ohno, unpublished results.

22. S. Miyamoto and N. Imai, Biophys. Chem., 11, 91 (1980).

23. P. J. Flory and J. E. Osterheld, J. Phys. Chem., 58, 653 (1954).

24. I. Noda, T. Tsuge, and M. Nagasawa, J. Phys. Chem., 74, 710 (1970).

25. M. Nagasawa and A. Holtzer, J. Am. Chem. Soc., 86, 538 (1964).

26. J. S. Tan and S. P. Gasper, Macromolecules, 6, 741 (1973).

27. J. E. Desnoyers and M. Arel, Can. J. Chem., 45, 359 (1967).

28. P. Assarsson and F. R. Eirich, J. Phys. Chem., 72, 2710 (1968).

29. S. L. Dygert, G. Muzii, and H. A. Saroff, J. Phys. Chem., 74, 2016 (1970).

30. P. L. Dubin and U. P. Strauss, J. Phys. Chem., 77, 1427 (1973). 